and $G-25671$ produced this effect in doses ranging from 150 to $300 \mathrm{mgm}$. However, $G-28315$ and $G-30249$, two of the strongest acids, were active in doses as low as $30 \mathrm{mgm}$. Further experiments were carried out to determine the maximum uricosuric effect produced by the rapid injection of a single large dose of drug. For example, the rapid injection of $800-1,000 \mathrm{mgm}$. of either phenylbutazone or G-27202 increased the ratio $C_{\text {uric acid }} / C_{\text {inulin }}$ two- to three-fold, whereas the injection of $400 \mathrm{mgm}$. doses of either $G-28315$ or $G-28234$ increased the clearance ratio seven- to eight-fold. In addition, the oral administration of $800 \mathrm{mgm}$. doses of phenylbutazone and $G-27202$ produced about a 30 per cent increase in the daily excretion of uric acid over the control values, whereas the same dose of $G-28315$ and $G-28234$ produced about a 125 per cent increase.

The values obtained for the half-life of the various analogues rule out the possibility that the weakly uricosuric analogues may be metabolized or excreted too rapidly to achieve effective plasma levels. The compounds which had the most potent uricosuric effect, such as $G-28315$ and $G-30249$, actually disappeared at a considerably more rapid rate (half-life $3 \mathrm{hr}$.) than phenylbutazone, $G-27202, G-15235$ and G-13838 (half-life 2-3 days). The larger dose of $G-32567$ required to produce the uricosuric effect than that needed for $G-28315$ and $G-28234$ may be due to its extremely rapid disappearance (half-life $1 \mathrm{hr}$.).

The potent uricosuric activity of the highly acidic phenylbutazone analogues indicates that these drugs act in the ionic form to block the reabsorption of uric acid by the renal tubule cells, thus furnishing a possible clue to the still obscure nature of the transport mechanisms involved. The demonstration that uricosuric activity in the phenylbutazone series is related to the $p K_{a}$, has proved of considerable aid in searching for new uricosuric drugs. One such drug, $G-28315$, has already been found to be useful clinically as a potent uricosuric agent in treatment of gout $2,5,6$.

We are grateful to Dr. Franz Haefliger and his colleagues of Geigy Pharmaceuticals, Basle, Switzerland, for the synthesis of the various phenylbutazone analogues used in this study.

$$
\begin{aligned}
& \text { J. J. Burns } \\
& \text { T. F. } \mathrm{YU} \\
& \text { Peter Dayton } \\
& \text { Lawrence Berger } \\
& \text { Alexander B. Gutman } \\
& \text { Bernard B. Brodie }
\end{aligned}
$$

The Laboratory of Chemical Pharmacology, National Heart Institute, Bethesda, Maryland;

The Departments of Medicine,

The Mount Sinai Hospital, and

Columbia University College of Physicians and Surgeons,

New York: and

The Research Service,

Third (New York University) Medical Division, Goldwater Memorial Hospital,

New York. Aug. 5.

${ }^{1}$ Flexser, L. A., Hammett, L. P., and Dingwall, A., J. Amer. Chem. Soc, 5 \%, 2106 (1935).

2 Burns. J. J. Yü, T. F., Ritterband, A., Perel, J. M., Gutman, A. B., Burns, J. J., Yü, T. F., Ritterband, A., Perel, J. M., Gutman, A. B..
and Brodie, B. B., J. Pharm. Exp. Therap., 119, 418 (1957). Tï T. Frodie, B. Burns, J., J., Paton, B. C. Gutman, A. B., and Brodie, Yü, T. F., Burns, J. J., Paton, B. C., Gutman, A.
B. B., J. Pharm. Exp. Therap., 123, 63 (1958).

‘̄ Burns, J. J., Rose, R. K., Goodwin, S., Reichentha1, J., Horning, E. C., and Brodie, B. B., J. Pharm. Exp. Therap., 113, 481 (1955).' ${ }^{5}$ Gutman, A. B., and Yü, T. F., Lancet, ii, 1258 (1957).

- Ogryzlo, M. A., and Harrison J., Ann. Rheumatic Dis., 16, 425 (1957).

\section{Decay of Immediate Memory with Age}

Current theory tends to emphasize the importance of interference in forgetting and to minimize the role of time lapse in the decay of the memory trace. Conrad $^{1}$, however, has recently shown that the immediate recall of eight-digit numbers is better when the numbers are presented and reproduced by subjects at a fast rate than when they are presented and reproduced at a slow rate. $\mathrm{He}$ interprets this finding as indicating that simple decay of the memory trace is an important factor in the loss of immediate memory.

In the course of a more complex investigation of the relation between age and ability to retain for short- and long-term periods various classes of material, I tested two groups of subjects for their ability to retain eight-digit numbers when presented and reproduced at different rates. Group $A$ consisted of 26 teachers, aged 18-29, drawn from different regions of Canada. Group $B$ consisted of 26 teachers, aged 30-55, also drawn from different regions of Canada, and matched as closely as possible with Group $A$ in general background, marks on university summer-school courses, and tests of remembering.

The results confirmed Conrad's finding that immediate recall is better when the numbers are presented and reproduced by subjects at a fast rate (120 digits per min.) than when they are presented and reproduced at a slow rate (40 digits per min.). The mean fraction of digits recalled at the slow rate was 0.475 , and at the fast rate 0.543 . These scores are both better than those reported by Conrad, but the samples in the present experiment are probably drawn from populations of higher intelligence, and the rates of presentation are slightly faster than in Conrad's experiment, both factors being likely to improve the scores on an immediate memory task.

Analysis of the results shows that there is no significant difference between the two groups in the proportion of digits recalled at the fast rate, but that there is a significant difference between the two groups $(P=0.05)$ in the proportion of digits recalled at the slower rate. The actual figures are given in Table 1.

Table 1

\begin{tabular}{|c|c|c|}
\hline \multirow{2}{*}{ Group } & \multicolumn{2}{|c|}{ Proportion of digits recalled } \\
\hline$A$ & Slow rate & Fast rate \\
\hline$B$ & 0.51 & 0.575 \\
0.37 & 0.58 \\
\hline
\end{tabular}

If Conrad's technique is an adequate measure of the decay factor in immediate memory, and if the present finding is confirmed by further research, it appears that the span of immediate memory is the same for the two age groups, but that the rate of decay of immediate memory tends to increase with age.

This study was carried out while I was in receipt of a grant from the Department of Veterans' Affairs, Ottawa. Full details of the completed study will be published elsewhere. My thanks are due to Dr. J. M. Blackburn for his interest and encouragement.

Department of Psychology, D. C. FRASER* Queen's University,

Kingston, Ontario. June 23.

* Present address, Waterioo College, Waterloo, Ontario. ${ }^{1}$ Conrad, R., Nature, 179, 831 (1957). 